\title{
sciendo
}

\section{Wiggins on Practical Knowledge}

\author{
Henry Clarke \\ University College London
}

DOI: $10.2478 /$ disp-2016-0005

BIBLID [0873-626X (2016) 42; pp. 113-124]

\begin{abstract}
Wiggins' (2012) argument against propositional accounts of knowing how is based on a development of some considerations taken from Aristotle's Nicomachean Ethics. Aristotle argued that the knowledge needed for participation in an ethos cannot be codified in propositional form so as to let it be imparted to someone who did not already have it. This is because any putative codification would be incomplete, and require that knowledge in order to extend it to novel cases. On a reasonable interpretation of his argument, Wiggins claims that the same goes for practical knowledge in general, and that this shows that a propositional view of knowing how is incorrect. This paper shows that this argument is unsound.
\end{abstract}

\section{Keywords}

Knowing how, practical knowledge, intellectualism, David Wiggins, Aristotle.

\section{Introduction}

Wiggins (2012) proposes to argue for the conclusion that any propositional account of knowing how is incorrect. By 'knowing how' is meant the kind of state a subject is in when it can be said of them that they know how to do something. This is the state that one is in when one has facility in a practice, some level of skill in or command over an action or activity, such that one can be reasonably successful in one's attempts to carry it out. The general form of a propositional analysis is one that holds that one knows how to do something if and only if one knows some proposition. Usually, some scheme of proposition that involves the practice in question is specified. In this way, the propositionalist understands the possession of facility in a practice as the possession of information about the practice. The

Disputatio, Vol. VIII, No. 42, May 2016

Received: 10/11/2015 Revised: 25/04/2016 Accepted: 05/05/2016 
non-propositionalist view is one that Wiggins finds in some passages from Ryle (1949). This holds that facility in a practice is a state distinct from the possession of information about that practice, and instead understand it as some sort of complex of dispositions to act in certain ways. Wiggins finds the propositionalist view in ascendance, and proposes to show that there are demands on propositional accounts, inspired by some passages in Aristotle's Nicomachean Ethics, that present the propositionalist with a dilemma.

I will argue that this dilemma is not genuine, though the substance of Wiggins' argument exposes some interesting issues concerning how to think properly about the relationship between possessing facility in a practice and possessing information about a practice.

\section{The Aristotelian considerations}

The main substance of the argument Wiggins presents against propositional accounts of knowing how is a development of some demands on such an account that extend what we might call the Aristotelian considerations, taken from the Nichomachean Ethics. These considerations are supposed to show that a propositional codification of what Wiggins calls 'the Aristotelian norm of being and doing', (2012: 99) and elsewhere participation in an ethos, or ethike arete, is faced with a problematic dilemma.

Wiggins summarises the Aristotelian considerations like so:

There is no question of a simply propositional complete elucidation or precisification of the Aristotelian norm of being and doing... If the subject matter of the practical is indefinite in the way Aristotle claims, and if no finite specification or form of words (not even one deploying all the resources of deixis or demonstration) can project the judgements of the practically wise agent reliably and correctly into an open and indefinite future, then there must reside within the grasp that these agents have of the spirit in which they are to act... some component of which is inherently and irreducibly practical-cum-agential. (2012: 99-100)

The reason for this is that, in response to any proposed propositional elucidation of

the positive instructions and prescriptions, requirements and ideals by which the adherents of a given outlook live their life together (2012: 104) 
which elucidation is put in the form of

self-sufficient statements of the form 'It is always right, or just, or prudent, or sensible (etc.), when so-and-so, to do such-and-such an act' (2012: 104)

it can be argued that

seriously and strictly speaking, the resulting form of words will be false and remain false (open to simply outrageous counterexamples) however lengthy you make the specification of the so-and-so or the such-and-such. (2012: 104)

Although one might appeal to the inclusion of demonstrative indication or ceteris paribus clauses in the proposition to avoid this problem by restriction, Wiggins argues that

if you save [the proposed elucidation] in that way, you sacrifice all the generality attaching to the injunction or principle you began with. You are no longer in the business of characterising a whole outlook... (2012: 104)

Moreover,

How do we determine what it is for 'other things to be equal'? This is easy for one who is already party to the outlook... But in a context where an outlook or mentality is to be redescribed in propositional terms, that answer will only be available when the redescription is complete. (2012: 104-5)

So the appeal to such restrictions is tantamount to tacitly abandoning the project.

The Aristotelian considerations take the form of a dilemma: either the propositional characterisation of ethike arete will be open to counter-examples, and hence will be extensionally inadequate; or it can be saved from these counter-examples, but only at the cost of the new characterisation presupposing the knowledge that is supposed to be characterised, and so cannot be used to get someone into a state of ethike arete who was not in it before, and hence it is instructionally inadequate. ${ }^{1}$

Wiggins says that he will "engage the philosophy of Aristotle with that of Gilbert Ryle", though he does not outline exactly how this is to go. An indication is offered in the following passage:

${ }^{1}$ This is not Wiggins' term; I expand on this point below. 
In what follows, a substantial part of the argument will turn upon examples where the doings, activities, or performances in question (like the doings of the Aristotelian phronimos) involve a large and indefinite plurality of considerations or concerns that have to be consulted or drawn upon and kept simultaneously in play. These offer some of the most salient or interesting obstacles to any wholesale reduction of other kinds of knowing to propositional knowing. (2012: 107)

The substance of Wiggins' objection to propositionalism about knowing how seems to be that the Aristotelian considerations in favour of the conclusion that ethike arete is irreducibly practical apply equally to knowing how. ${ }^{2}$ In which case, a dilemma similar to that outlined above would apply in the case of knowing how: either the proposed propositional knowledge involves content that is open to counter-examples, and hence is extensionally inadequate, or else can be saved but in a way that presupposes what is meant to be conveyed, and hence is instructionally inadequate.

The dilemma in the case of ethike arete was meant to show that it is to be properly understood as practical knowledge, ${ }^{3}$ which is consistently contrasted by Wiggins with propositional knowledge. ${ }^{4}$ The propositionalist could accept the distinction between practical vs. non-practical knowledge, but reject the further claim that the distinction tracked is the propositional vs. non-propositional knowledge distinction. If, on the other hand, the distinctions come together by stipulation, as seems to be the case in Wiggins' discussion, the propositionalist may reject the claim that knowing how is practical knowledge. So Wiggins needs to show, in a non-question begging

${ }^{2}$ There is much else in the paper that concerns arguments that have been given for propositionalism, and positive suggestions about how having information relevant to a practice might itself depend on facility in the practice. I set these aside for present purposes.

${ }^{3}$ Wiggins says he prefers the terms 'agential' or 'practical-cum-agential' knowledge (see 2012: §12), though I will stick to 'practical'. Practical knowledge in the sense employed by Wiggins is to be distinguished from Anscombe's (1957) notion of non-observational knowledge of what one is doing; see Setiya (2008; 2012) for discussion of the relationship between these.

${ }^{4}$ Wiggins also expresses the view that "in their however well motivated preoccupation with knowing how, Ryle or his followers have narrowed unduly the scope of the practical/agential.” (2012: 113) 
way, that knowing how is practical knowledge in the stipulated sense, and we may assume that this is what applying the Aristotelian considerations to the case of knowing how is supposed to show.

One might worry about whether what I have just said is a fair interpretation of how Wiggins' applies the Aristotelian considerations. 'Instructional adequacy' is not Wiggins' term, and nor does he explicitly formulate a demand of that sort. However, a basis for interpreting Wiggins' argument against propositionalism in this way, as indeed concerning a dilemma of extensional and instructional adequacy, can be found reasonably clearly in some questions he raises for the propositionalist in the light of the examples he gives.

Of the case of someone called Hannah who knows how to ride a bike, he asks:

Would [propositionalism] help to show that Hannah's competence, her knowing how to ride a bicycle, was "piloted by [the] intellectual grasp" of the true proposition which conveys the information that [propositionalists] credit her with having and acting by? [...] How could it show that Hannah's grasp as they describe it is not rather, as Ryle might have proposed, the "stepchild" of the know-how itself? (2012: 118; emphasis added)

Shortly after, a further question is raised with regard to a case he describes, of an experienced ship's pilot giving advice to someone without their experience about how to deal with a particular situation in bringing a ship into a harbour:

Could some extension or elaboration of the advice that he offers for the special case where the wind is from the north and the tide is ebbing spell out everything that is involved here? Could this elaboration be set out as a practically effective and immediately enactable procedure...? (2012: 119; emphasis added)

We also get the example of a retiring senior partner at a family firm, who needs to communicate how the firm is to be run to his successor:

The thing that [the outgoing senior partner] cannot do is to reduce all the things that he practically knows into a form of words representing the whole way in which he achieved what he achieved or a complete guide or instruction book for his successor. There is no proposition, no conceivable form of words, that answers to and condenses his way of running the show. Nor is there any way of doing things that he can demonstrate 
or put on display. When he advises his successor, what he reads off from his experience and know-how furnishes insufficient materials for an 'operating manual' for competent performance by the senior partner. It cannot condense the whole substance of his control of an indefinite spread of possible contingencies. (2012: 119-120; emphasis added)

That Wiggins emphasises the giving and using of advice, instructions, or guides to achieve skilful action, and asks whether such a thing is possible, indicates that he is imposing the demand of instructional adequacy on the propositionalist, since that demand links the possession of information to practical activity.

It is important to note, as does Wiggins, that the examples concern actions which express, exploit, or otherwise manifest the relevant knowledge. They are in the first place examples of exercises of the agent's knowing how to do something. ${ }^{5}$ So there must be a way of getting the examples to show something about the nature of knowing how itself, as opposed to exercises of knowing how. If there is a dilemma for propositional accounts of knowing how, then something needs to be shown to link these doings with the sort of knowledge in question, to demonstrate that the dilemma applies. Wiggins' concern with the problem of conveying knowledge makes this link, and is relevant only if what is being demanded of the propositional account of knowing how is something like instructional adequacy. And if the demand for instructional adequacy applies, then presumably so too does the demand for extensional adequacy, since, in the context of the Aristotelian considerations, the issue of instructional adequacy arose as a result of the failure to achieve it.

I conclude that Wiggins can be reasonably interpreted as pressing something like the dilemma found in the Aristotelian considerations against the propositionalist. ${ }^{6}$

\footnotetext{
${ }^{5}$ Compare the quotation above: 'a substantial part of the argument will turn upon examples [of] doings, activities, or performances'. (2012: 107; emphasis added)

${ }^{6}$ There is perhaps room for other interpretations in Wiggins' sometimes allusive discussion; I submit that the interpretation offered here makes most sense of his appeal to the Aristotelean considerations.
} 


\section{Evaluating the dilemma}

I will now show that the dilemma is not a genuine one.

To begin with the first horn, it is not clear that the examples Wiggins supplies give reason to think that propositionalism faces a problem with extensional adequacy. Certainly, no principled reason is given for thinking that, for any proposition that might be specified as the content of some state of knowledge that the agents in the examples are alleged to possess, that proposition would be open to counter-examples. Nor do the examples suggest ways in which counter-examples to the propositions that feature in the propositionalist's analyses might come about.

There is a good reason for this: the propositionalist is not committed to specifying propositions of the sort that would be open to counter-examples of the kind that Wiggins envisions. A comparison with the Aristotelian considerations helps here. A propositional characterisation of ethike arete consists of giving rules, of the form 'it is always right to do action A in circumstances C'. A proposed rule is counter-exampled by cases that match those circumstances but in which it would not be right to do that action. By contrast, a propositional account of knowing how need not specify propositions that provide rules that would need to cover potentially varying circumstances. It does need to specify contents of states that can be exercised in action, which exercises can be successful in some circumstances. But then they are not open to counter-examples, at least not in the same way that putative rules are, in virtue of the "indefinite spread of contingencies", which is what the examples are meant to suggest.

Consider the by now most well-known propositional account, due to Stanley and Williamson (2001). They propose that

(SW) S's knowing how to $\varphi$ consists in $\mathrm{S}$ knowing that $\mathrm{w}$ is a way of $\varphi$-ing.

How might a proposition like the one that appears on the right hand side be extensionally inadequate? Presumably on the condition that $\mathrm{w}$ is not a way of $\varphi$-ing. But what would this involve? That $\mathrm{w}$ is not always a way of $\varphi$-ing, a way that can be employed in all circumstances in order to $\varphi$, is not to the point. One can know that $w$ is a 
way of $\varphi$-ing, attempt to $\varphi$ in that way, and be reasonably successful in doing so, even if it is not a way of $\varphi$-ing successfully in all cases. This shows nothing about the cogency of the account.

This points to a difference between the task of characterising what it is to participate in an ethos and that of giving a propositional account of knowing how, one that is obscured by assimilating them both to the broader category of practical knowledge.

It is worth noting the shape of the dialectic at this point. In the Aristotelian considerations, the worry about instructional inadequacy got going because of extensional inadequacy. Can the worry about instructional adequacy in the case of knowing how, the second horn of the dilemma, be preserved even though the first horn is not genuine? Arguably, yes. Recall that extensional inadequacy was to be avoided by employing ceteris paribus clauses and what Wiggins calls resources of deixis or demonstration; in other words, some nondescriptive element or direct reference to actions. The thought could then be that, while ceteris paribus clauses are irrelevant, non-descriptive resources are needed despite the absence of problems with extensional adequacy.

Consider again (SW), according to which knowing how is knowing of some way that it is a way of doing an action. The way figures de re, as it were; referred to without being described. ${ }^{7}$ An agent who knows how to do something might not be able to describe how they do what they do. If one knows something in a descriptive way only if one can give a description, then the agent's knowledge is non-descriptive. Perhaps any viable account will need to allow for this. So we can assume, for the sake of argument, that propositional accounts do require non-descriptive reference to actions. In which case, the worry about instructional adequacy would get going even without extensional inadequacy. This suggests that the second horn of the dilemma is still viable. But it is not clear that instructional adequacy is really an issue.

It is worth touching on Ryle's discussion at this point. The idea that there is no proposition that is instructionally adequate is similar to Ryle's regress argument in The Concept of Mind:

\footnotetext{
${ }^{7}$ Stanley and Williamson (2001) put this in terms of practical modes of presentation, an idea developed by Stanley (2011).
} 
The consideration of propositions is itself an operation the execution of which can be more or less intelligent, less or more stupid. But if, for any operation to be intelligently executed, a prior theoretical operation had first to be performed and performed intelligently, it would be a logical impossibility for anyone ever to break into the circle. (1949: 31)

Ryle's regress argument was directed against what he called the intellectualist legend, or intellectualism. This is a position on how intelligent or skilful activity is carried out, to the effect that intelligent activity is preceded by prior acts of consciously considering propositions about how to do the relevant action. Propositionalism, by contrast, is a position on the nature of a kind of state that can be exercised in action, not about what happens in order for that state to be exercised. ${ }^{8}$

Imposing the demand for instructional adequacy conflates issues germane to propositionalism to those germane to intellectualism. There is no obvious reason to think the propositionalist is committed to saying anything about the psychological processes undergone in the exercise of knowing how, or how someone might come to be in a position to do so. So when Wiggins asks

Would [propositionalist arguments] help to show that Hannah's competence, her knowing how to ride a bicycle, was "piloted by [the] intellectual grasp" of the true proposition which conveys the information that [propositionalists] credit her with having and acting by? (2012: 118)

the propositionalist can deny they are trying to show any such thing, if being piloted by the intellectual grasp of a true proposition means consciously entertaining and then acting on some information about how to achieve success in bringing off one's intentions.

The point I wish to make is that the charge of instructional inadequacy seems to be predicated on the thought that propositionalism about knowing how entails intellectualism about action. One might grant that the relevant propositions are not instructionally adequate, but insist that this is only a problem if propositionalism implies intellectualism. Something must be said to show that the latter bears on

\footnotetext{
8 'Intellectualism' is commonly used as the label for what I have been calling 'propositionalism' (Stanley and Williamson 2001 being a good example). The terminology is less important than the point that claims about the state of knowing how are logically distinct from claims about episodes of exercising it.
} 
the former. It is unclear what this could be.

One reason Wiggins might have is his assimilation of both knowing how and ethike arete to the broader category of practical knowledge. If I have understood it properly, however, the dilemma was meant to provide non-question begging reasons for thinking that knowing how can assimilated to the category of practical knowledge, so it cannot be based on that assimilation. Moreover, we have seen a reason to think that this assimilation is faulty. And further, the propositionalist might well be motivated simply to deny that commitment if they accept Ryle's argument that it threatens to open up a regress. There is no reason to take on a commitment not essential to one's theory that potentially threatens it, and so there is no reason to think that a propositional account of having facility in a practice and a propositional characterisation of what it takes to participate in an ethos face similar problems. The propositionalist can, therefore, reject the demand of instructional adequacy, and need not show that it can be met.

It might be objected that an account of knowing how must make at least some commitments about the way in which knowing how can be exercised; at the very least, propositionalism is committed to the idea that the content of the alleged propositional knowledge is involved in the psychological process leading up to actions that exercise it. It is not obvious that this is correct, ${ }^{9}$ but suppose we grant it for the sake of argument. Does this point help Wiggins' case?

We should distinguish moderate intellectualism, ${ }^{10}$ that explains action that expresses knowing how as being guided by states with propositional content, from strong intellectualism, that explains action in terms of states with propositional content of a sort that require

${ }^{9}$ See Dickie 2012 for related discussion on this point.

${ }^{10}$ This is what Stanley (2011: 14) calls 'reasonable' intellectualism, which he endorses (2011: 14-25, 184-5). On Stanley's view, knowing that $w$ is a way of $\varphi$-ing can guide one's attempts to $\varphi$ through automatic mechanisms, not intelligent actions, that apply the knowledge when an agent intends to carry out an action. Stanley's account comes close to intellectualism of the form that Ryle was arguing against, but the differences should not be overlooked. The intellectualist legend that Ryle attacked holds that guidance is a matter of considering propositions, where such considering is not automatic but rather a potentially intelligent act itself. This is stronger than Stanley's notion of guidance. 
capacities to produce and understand sentences that express those propositions. Strong intellectualism requires being able to discursively convey the propositions. In the case of moderate intellectualism, there is no commitment, as Fridland (2013: 887) says, to the view that "the intelligence of a skill must be entirely accounted for in propositional terms", since that would be to simply conflate propositionalism with strong intellectualism about knowing how.

With the distinction between strengths of intellectualism in mind, there is a question about what form might be required by propositionalism for it to be defensible. ${ }^{11}$ A version of this question also arises for Wiggins. It seems that the demand of what I have called instructional adequacy, the demand that a propositionalist explanation of actions that exercise knowing how must be given in terms of propositions that can be conveyed and grasped, indicates that he assumes, if only tacitly, that propositionalism requires strong intellectualism. Even supposing that the propositionalist is committed to some form of intellectualism, the propositionalist can consistently deny the strong commitment.

\section{Conclusion}

A propositional view of knowing how does not come with the obligation to supply propositions to serve as rules, or to supply propositions that can be used as instructions. These points show that knowing how and ethike arete differ in some important respects. Wiggins' argument against propositionalism based on the Aristotelian considerations ignores the differences between knowing how and ethike arete, and conflates propositionalism with strong intellectualism. It should therefore be rejected as unsound. ${ }^{12}$

Henry Clarke Department of Philosophy University College London

\footnotetext{
${ }^{11}$ See Stalnaker 2012 for discussion in relation to Stanley's account.

${ }^{12}$ Thanks to Paul Snowdon for originally prompting me to write this paper; thanks also to audiences at UCL and an anonymous referee for helpful comments on earlier drafts.
} 


\section{References}

Anscombe, E. 1957. Intention. Oxford: Basil Blackwell.

Dickie, I. 2012. Skill before knowledge. Philosophy and Phenomenological Research 85: 737-745.

Fridland, E. 2013. Problems with intellectualism. Philosophical Studies 165: 879 891.

Ryle, G. 1949. The Concept of Mind. London: Hutchinson.

Setiya, K. 2008. Practical knowledge. Ethics 118: 388-409.

Setiya, K. 2012. Knowing how. Proceedings of the Aristotelian Society 112: 285-307

Stalnaker, 2012. Intellectualism and the objects of knowledge. Philosophy and Phenomenological Research 85: 754-761

Stanley, J. and Williamson, T. 2001. Knowing how. The Journal of Philosophy 98 : 411-444

Stanley, J. 2011. Know How. Oxford: OUP.

Wiggins, D. 2012. Practical knowledge: knowing how to and knowing that. Mind 121: 97-130. 